Cómo citar este artículo en MLA: Mazo Lopera, John Edison y Alveiro Valencia Ramírez. “El caballo viejo. Interpretaciones filosóficas y políticas de una fábula”. Escritos 28. 60 (2020): 15-28. doi: http://dx.doi.org/10.18566/escr.v28n60.a02

Fecha de recepción: 20.09.2019

Fecha de aceptación: 03.02 .2020

\title{
El caballo viejo. Interpretaciones filosóficas y políticas de una fábula ${ }^{1}$
}

\author{
The Aged Horse Philosophical and political interpretations of a fable
}

\author{
John Edison Mazo Lopera ${ }^{2}$ \\ Alveiro Valencia Ramírez $z^{3}$
}

\section{RESUMEN}

En el contexto de una didáctica para el aprendizaje y la actualización de los textos y las lenguas clásicas, este trabajo propone una traducción e interpretación del sentido filosófico y político de la fábula El caballo viejo, de Babrio. La traducción sigue la versión griega de Crusius (1897) y la edición de Gredos (1985), mientras que la interpretación de la fábula se apoya en las reflexiones filosóficas y políticas de Cicerón y Plutarco en De la vejez y Sobre si el anciano debe intervenir en política. Estas reflexiones se constatan, además, desde un análisis estadístico sobre Los longevos, de Luciano de Samosata. Así pues, el sentido de la fábula dice que los jóvenes estadistas deben evitar convertirse en los próximos políticos inútiles o "caballos viejos" del Estado. Esta reflexión contribuye hoy a sopesar la participación política de los jóvenes y actualiza la importancia cívica de los ancianos en su intervención sobre los asuntos públicos.

Palabras clave: Filosofía; Política; Fábula; Vejez; Juventud; El caballo viejo; Babrio.

\section{ABSTRACT:}

In the context of a didactic for learning and updating the texts and classical languages, this work proposes a translation and interpretation of the philosophical and political sense of the fable The Aged Horse of Babrius. The translation follows the Greek version of Crusius (1897) and the Gredos edition (1985), while the interpretation is

1 El presente artículo se deriva del proyecto de investigación "Didáctica de las lenguas clásicas: enseñanza y aprendizaje en la formación universitaria" (137C-05/18-42) de los grupos de investigación Epimeleia de la Escuela de Teología, Filosofía y Humanidades de la Universidad Pontificia Bolivariana, Medellín, Colombia.

2 Candidato a PhD. en Historia por la Universidad Nacional de Colombia, sede Medellín, Magíster en Historia por la misma Universidad, y Filósofo de la Universidad de Antioquia. Docente de la Facultad de Filosofía de la Escuela de Teología, Filosofía y Humanidades de la Universidad Pontificia Bolivariana, Medellín. Integrante del grupo de investigación Epimeleia de la UPB. Correo electrónico: john.mazol@upb.edu.co

3 Candidato a PhD. en Filosofía por la Universidad Pontificia Bolivariana, sede Medellín. Docente de la Facultad de Filosofía de la Escuela de Teología, Filosofía y Humanidades de la Universidad Pontificia Bolivariana (UPB), Medellín. Integrante del grupo de investigación Epimeleia de la UPB. Correo electrónico: alveiro.valencia@upb.edu.co 
based on the philosophical and political reflections of Cicero and Plutarch in On old Age and Whether an old man should engage in plublic affairs. These reflections can also be seen from a statistical analysis of Long-Lived Men of Lucian of Samosata. Thus, the meaning of the fable says that young statesmen should avoid becoming the next useless politicians or "old horses" of the State. This reflection contributes today to weigh the political participation of young people and updates the civic importance of the elderly in their intervention on public affairs.

Keywords: Philosophy; Politics; Fable; Old age; Youth; The Aged Horse; Babrius.

\section{Introducción}

$\mathrm{L}$ a fábula se puede entender como un relato breve en el que intervienen protagonistas de distinta naturaleza (dioses, humanos, animales y plantas) y del que se desprende que lo ocurrido puede volver a repetirse. ${ }^{4}$ Desde sus inicios este género literario, según Rodríguez Adrados, se caracterizó en Grecia como un género popular y crítico en contra de la tiranía o el abuso del poder ("Política Cínica" 419). ${ }^{5}$

Su desarrollo histórico, según B. E. Perry, comprende tres periodos: el primero trata sobre la compilación de fábulas esópicas elaborada por Demetrio de Falero en el siglo IV a.C.; seguido por las obras de compilación que caracterizan la literatura del periodo helenístico y, finalmente, un tercer periodo con la influencia de Fedro y Babrio (394).

Este último fabulista fue un hombre culto y conocía de literatura griega, clásica y helenística que posiblemente vivió durante el siglo I d.C. ${ }^{6}$ Entre sus fábulas se encuentra un pequeño relato que, en la edición de Gredos (1985), se titula El caballo viejo. Esta fábula no tiene paralelo con ninguna de las 273 fábulas atribuidas a Esopo en esta edición. Por este motivo, merece un comentario que amplíe el sentido de su epimythium o "moraleja" que, con el uso del simbolismo político del caballo, pretende evitar que los jóvenes aspirantes a la carrera política se conviertan en futuros estadistas inútiles o los "caballos viejos" del Estado. ${ }^{7}$

Para desarrollar esta interpretación se tiene en cuenta la edición griega de Crusius (1897), la traducción en castellano de la editorial Gredos (1985) y se procede del siguiente modo: en primer lugar, se transcribe la narración en griego y se traduce al castellano; luego, se estudia sintáctica y morfológicamente la fábula; posteriormente, se despliega un comentario hermenéutico sobre la vejez y se articulan, respectivamente,

4 Rodríguez, Adrados F. "La fábula griega" 35-6. Sobre los orígenes de la fábula griega, véase Rodríguez Adrados "Más sobre la fábula 346-7.

5 La fábula El caballo viejo puede vincularse con las críticas de la política cínica que caracterizan a las fábulas esópicas analizadas por Rodríguez Adrados ("Política Cínica" 1987). El ideal filosófico de la autarquía puede leerse entre líneas si se considera que los jóvenes deben gobernarse a sí mismos para evitar convertirse en políticos inútiles o "caballos viejos" del Estado. Sin embargo, durante el análisis de la fábula se dará otra explicación con base en las opiniones filosóficas de Cicerón y Plutarco.

6 Sobre la vida de Babrio, véase la introducción general en la edición de Gredos 1985.

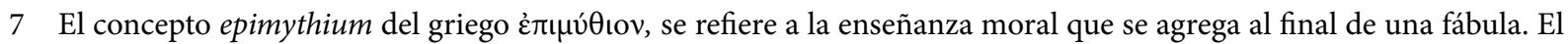
procedimiento inverso que introduce la moraleja en el inicio del relato se conoce como $\pi \rho \mu_{\mu v} \theta$ เov. Sobre un estudio detallado de estos conceptos, véase Perry, B. E. “The Origin” 391-419. 
las opiniones filosóficas de Cicerón y Plutarco en De la vejez y Sobre si el anciano debe intervenir en política. Para finalizar, se presenta un breve análisis estadístico sobre la longevidad a partir de una obra de Luciano que lleva por título Los longevos, con el propósito de corroborar los argumentos de aquellos filósofos.

\title{
Transcripción y traducción
}

\author{
Versión en griego de Crusius (1897):

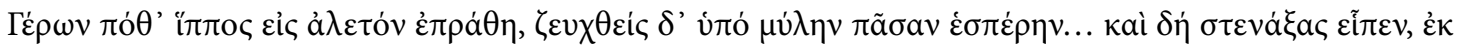

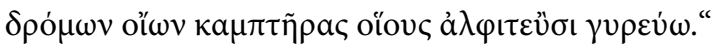

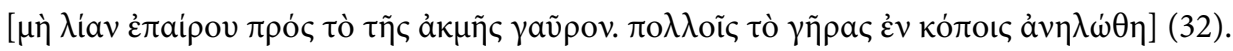 \\ Versión en castellano de Bádenas y López (1985): \\ Una vez, un caballo viejo fue vendido para moler y, uncido a la muela, se pasaba toda la tarde moliendo. \\ Entonces, suspirando, dijo: «¡Y pensar en aquellas carreras del hipódromo...! ¡A qué metas tengo que dar \\ vueltas ahora para estos molineros!». \\ No te ensalces demasiado en la arrogancia de la juventud, porque para muchos la vejez transcurre entre \\ miserias (318-319).
}

Ejercicio de traducción propio:

Había una vez un viejo caballo que fue vendido para la molienda, habiendo sido puesto toda la tarde a yugo en el molino, suspiró profundamente y dijo: "pensar en las curvas de las carreras y ahora solo doy vueltas en círculo para los molineros".

No te enorgullezcas demasiado por la vanidosa fuerza de la juventud, pues a muchos la vejez los ha consumido con fatigas.

\section{Análisis sintáctico y morfológico}

La narración está encabezada por el adjetivo $\gamma \dot{\varepsilon} \rho \omega \nu$ que significa ser viejo. La vejez es el atributo del caballo y entre este sustantivo y su adjetivo se encuentra la partícula enclítica $\pi$ ó $\theta$ ' del adverbio $\pi$ o $\varepsilon \dot{~ q u e ~}$ ha perdido la épsilon $(\varepsilon)$ ante la vocal inicial del sustantivo ï $\pi$ roç. Este fenómeno se conoce como elisión y se utiliza como signo el apóstrofe (') al final de la palabra (Berenguer 24). Este mismo fenómeno de supresión sucede más adelante con el adverbio $\delta$ ń ante la preposición úró ( $\delta$ ' vंđó).

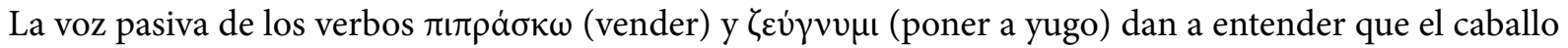
ha sido sometido a una condición de esclavitud. Este animal, al parecer, era un caballo de competencias deportivas, pues la fábula dice que él piensa en las curvas ( $\alpha \mu \pi \tau \tilde{\eta} \rho \alpha \varsigma)$ de las carreras $(\delta \rho o ́ \mu \omega v)$. Sin embargo, ahora se lamenta porque es un esclavo que solo puede dar vueltas en el molino.

En el inicio de la fábula se puede reconocer la causa de su desgracia: la vejez ( $\gamma \dot{\varepsilon} \rho \omega v)$. En la narración se presentan dos momentos sobre la imagen de este animal. Uno, en el que se recuerda como caballo de carreras y otro en el que se reconoce como el caballo del molino. Cada uno se relaciona con la juventud del pasado y con la vejez del presente. Posiblemente, el molino de la fábula alude analógicamente a la 
vida privada y campestre, mientras que las carreras de competencia ( $\delta \rho o ́ \mu \circ)$ se refieren a la vida pública. En relación con este cambio de escenarios, se puede emparentar esta interpretación con las palabras de Plutarco cuando critica a los ancianos consagrados a oficios campestres tras haber abandonado las actividades civiles y políticas de la vida pública (Sob. Anc.784a). Y vale decir que, en este sentido, la vida política está representada en la fábula con el $\delta \rho o ́ \mu o \varsigma$, mientras el molino representaría la vida campestre. Además, desde la crítica de Plutarco es notorio cómo el paso de la vida pública al de la vida campesina es un signo de retroceso en términos políticos para la carrera de los estadistas: hombres de edad avanzada que Platón había vinculado metafóricamente con la imagen del caballo (República III, 413d). ${ }^{8}$

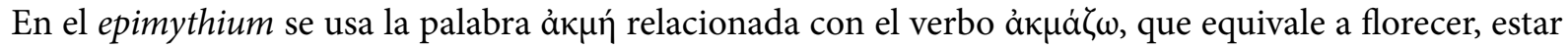

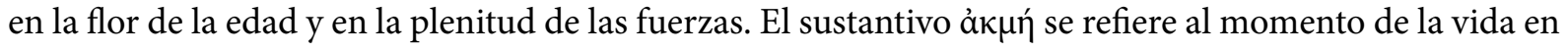
el que las fuerzas de la juventud están en todo su vigor. Pero en la fábula se menciona otro momento de

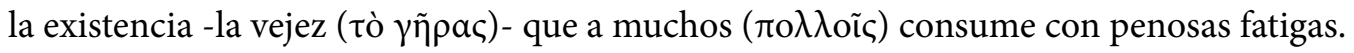

En este relato, la fuerza de la vida o el florecimiento de la existencia (’ak $\mu \eta \dot{)}$ se relaciona con la juventud. La vejez ( $\gamma \tilde{\eta} \rho \alpha \varsigma)$, en cambio, se caracteriza por la dificultad, la desgracia, la pena, el sufrimiento, el

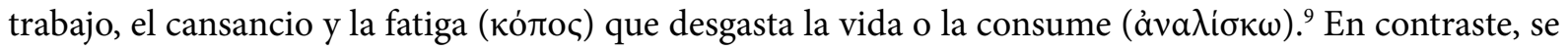
puede decir que a la fuerza del joven le corresponde el juego, la carrera, la competencia y la meta, pero al viejo le espera como destino una condición penosa y desgraciada lejos de la vida pública, representada en la fábula por el $\delta \rho o ́ \mu o c$.

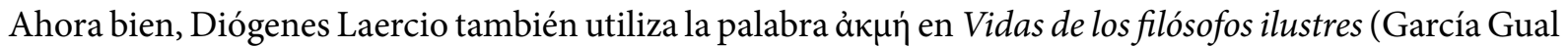
13). ${ }^{10}$ En este caso, el florecimiento de la vida no se relaciona con la juventud, sino con la vejez. Gracias a esta pista es legítimo preguntar: ¿la flor de la vida (åk $\mu \eta \dot{)}$ se encuentra en la juventud o corresponde a la etapa final de la existencia?

La moraleja de la fábula dice: "No te enorgullezcas demasiado por la vanidosa fuerza de la juventud, pues a muchos la vejez los ha consumido con fatigas". ¿Qué significa esto? ¿La vejez es una condición miserable de la vida? ¿La moraleja quiere decir que los jóvenes son los únicos que están en condiciones favorables para la vida pública y los éxitos? Y, en términos generales, ¿los jóvenes deben ocuparse de la política mientras que los ancianos deben ser apartados de la "cosa pública" por su debilidad física?

De seguro la fábula es una invitación a pensar sobre las fuerzas de la juventud y una insinuación para tener presente las dificultades que acarrea la vejez. Sin embargo, el sentido del epimythium puede decir algo más sobre aquellas inquietudes que han surgido y que fueron tratadas en su momento por Cicerón y Plutarco. Ambos filósofos reflexionaron sobre el tema y, por eso, se analizan a continuación los tratados que llevan por título: Sobre la vejez y Sobre si el anciano debe intervenir en política (en adelante Sob. Anc.)

8 El caballo es el símbolo por excelencia de la vida política y también un emblema de la soberanía para los antiguos. Cf. Raquena 52.

9 Sobre la percepción miserable y desgraciada de la vejez en la antigua Roma cf., Torrego 216.

10 Carlos García Gual traduce ảk $\mu$ ṕ por “florecimiento”. 


\section{Comentario hermenéutico}

Las reflexiones filosóficas de Cicerón y Plutarco permiten considerar que el florecimiento de la vida,

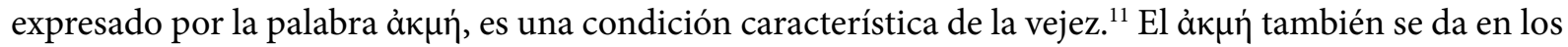

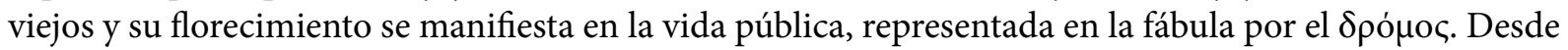
esta consideración, la vejez debería entenderse en términos no peyorativos.

Ahora bien, el epimythium invita a reflexionar sobre la vida de los ancianos diciendo que: "a muchos la vejez los ha consumido con fatigas". Sin embargo, existe el contraste en cuanto que a otros ancianos no los ha consumido, sino que los ha hecho brillar como ejemplos de virtud.

Entre líneas la fábula invita a reflexionar sobre aquellos ancianos que cuidaron con prudencia las fuerzas de la juventud y que, como exemplum positivo de la moraleja, evitaron para sí mismos las penas y las fatigas de la vejez y convirtieron su existencia en una condición longeva tan deseable como admirable por todos los ciudadanos.

La fábula parece hacer entender que la longevidad del caballo se caracteriza por la pena, la fatiga, el sufrimiento, el trabajo y el cansancio (ко́лоৎ). Estos golpes de la vejez expresan incapacidad, insuficiencia, inhabilidad y descalificación al anciano tal como lo indica el dicho popular: "loro viejo no aprende a hablar". En este caso, el "loro viejo" hace acento en la condición desvalida del hombre viejo.

En la época de Cicerón (siglo I. a.C.) surgen pensamientos semejantes en contra de la senectud dirigidos por jóvenes políticos quienes, al parecer, rechazaban la condición miserable de la vejez por cuatro motivos: a) aparta de administrar los negocios, b) hace más débil el cuerpo, c) priva de casi todos los placeres y, d) no está lejos de la muerte (Cicerón De la vejez 15).

Estos argumentos son ataques apoyados en opiniones populares que requerían tratamiento filosófico para una sociedad cuyo Estado se fundó con ayuda de la inteligencia (mens), la razón (ratio) y el consejo (consilium) de los ancianos. Sin ellos no existirían las ciudades, como dice Cicerón: "mens enim et ratio et consilium in senibus est, qui si nulli fuissent, nullae omnino civitates fuissent” (Cicerón De la vejez 67). Y, por otra parte, se menciona que: "en efecto el nombre de la patria es el primero y más familiar de todos,

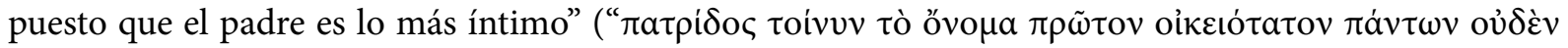

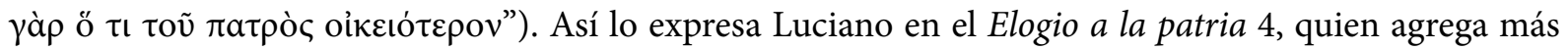

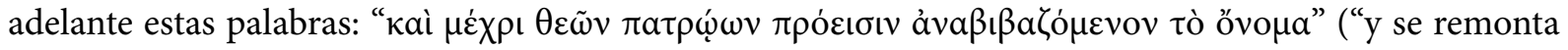
hasta el nombre de los dioses de la patria"). ${ }^{12}$

Si en realidad los antiguos pensaron de este modo, entonces, no es extraño que los ancianos y la patria llegaran a constituirse como figuras sagradas tanto en Grecia como en Roma. Y su sacralidad, por supuesto, se asocia con los mejoramientos que ellos aportaron a la vida pública. Al respecto, para citar

11 Es complejo determinar la edad que corresponde a la etapa de la vejez para los antiguos, especialmente porque la única fuente que trata directamente el tema es De la vejez de Cicerón en la que no se aportan muchos datos sobre la edad de los ancianos. Sin embargo, a partir de esta misma fuente se puede aventurar una edad aproximada entre los 40-50 y 60 años. Cf., Torrego 211.

12 Sobre el papel misterioso y sagrado del padre de familia en la antigua Roma, véase Coulanges 27-32. 
un ejemplo, cuenta Diógenes Laercio que Epiménides de Creta (c.600 a.C.) fue enviado por su padre a buscar una oveja, pero el joven se desvió del camino a medio día y se durmió en una cueva en la que, trascurridos cincuenta y siete años despertó (Epiménides 109). En adelante inicia el relato de las obras y las acciones que hicieron de Epiménides alguien memorable por sus aportes a las ciudades griegas y por todos considerado como el hombre más amado por los dioses ( $\theta \varepsilon \circ \varphi \iota \lambda \dot{\varepsilon} \sigma \tau \alpha \tau \varsigma)$. Esta misma historia la

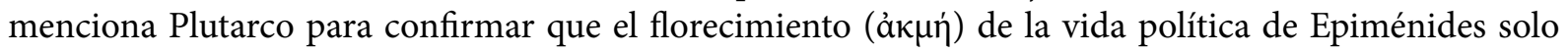
inicia en la vejez (Sob. Anc. 784a).

Muchas otras vidas florecieron en edad avanzada. Pericles alcanzó su mayor poder cuando era viejo (774e), al igual que Julio César (784d) y Pompeyo Magno (785f). También se dice que Simónides venció en un concurso coral cuando era viejo (785a), Filemón el cómico, Alexis y Polo, el actor trágico, no abandonaron el teatro durante la vejez (785b) y que Sófocles, en edad avanzada, continuaba componiendo sus obras (785ab). Por su parte, Cicerón dice que Platón murió a los 81 años escribiendo, que Isócrates vivió 99 años y escribió el Panatenaico, justo cuatro años antes de su deceso (De la vejez 13), y más adelante Cicerón agrega: "Homero, Hesíodo, Simónides, Estesícoro, Isócrates, Gorgias, Pitágoras, Demócrito, Platón, Jenócrates, Zenón, Cleantes, Diógenes el estoico... ¿los forzó la vejez a enmudecer en sus estudios? (23).” ${ }^{13}$

Estos ejemplos de hombres longevos atizan con intensidad la reflexión sobre la vejez y se apoyan en etimologías de lengua griega para aducir, según Plutarco, que el sentido de las palabras "honor"

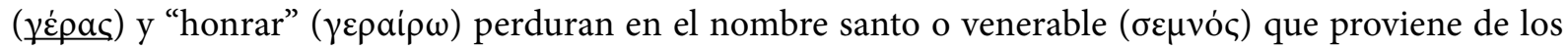
ancianos $(\gamma \dot{\varepsilon} \rho \omega \nu)$.

Este nombre dio lugar a la $\gamma \varepsilon \rho o v ́ \sigma ı$, institución política espartana integrada por hombres viejos que

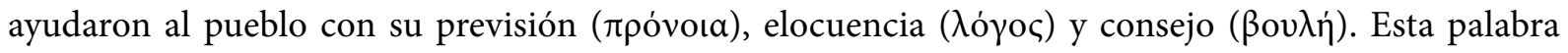
también define el Consejo ateniense ( $\beta$ ov $\lambda \dot{)}$ ) constituido por ciudadanos libres y ancianos ( $\pi \rho \dot{\varepsilon} \sigma \beta \cup \varsigma$ ), al igual que el Senado romano cuyo nombre se deriva de la palabra senex, es decir, anciano (Plut. Sob. Anc. 789d). ${ }^{14}$

Estas consideraciones permiten confirmar que, tanto en Grecia como en Roma, existió una relación relevante entre lo sagrado de la patria y los antiguos miembros del Estado (Torrego 213-214). Esto, indudablemente, sirvió de motivación a Cicerón y a Plutarco para escribir en contra de los argumentos que renegaron de la vejez. Para ambos filósofos dicha condición no es una excusa válida para apartarse o ser apartado de los negocios públicos por los siguientes motivos.

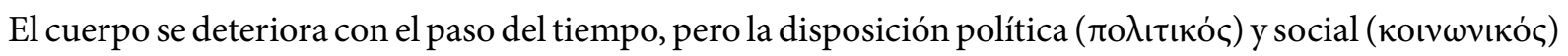
del hombre se renueva, se aumenta y difícilmente envejece con los años. Estas características las menciona Plutarco cuando compara la persistencia natural de la sociabilidad con la disposición para

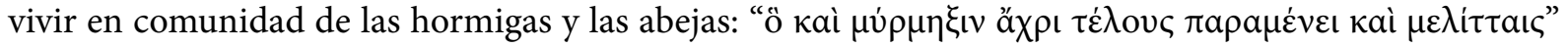
("esto persiste totalmente en las hormigas y en las abejas hasta el final" Sob. Anc. 783f). De igual modo, en el ser humano perduran estas capacidades durante toda su existencia y nunca se deterioran si se

13 Traducción de Julio Pimentel Álvarez (UNAM, 1997).

14 La institucionalidad que representan los ancianos en la antigüedad posiblemente fue el detonante de disputas y críticas contra la vejez por parte de una juventud hambrienta de poder tanto en Grecia como en Roma. Estos síntomas se pueden rastrear a partir de la percepción del anciano en la literatura antigua. Cf., Torrego 216. 
las conserva con educación y esfuerzo. Dicho así, en la vida bien llevada del hombre viejo (ảvń $\gamma$ $\varepsilon \dot{\rho} \omega v)$ se manifiestan con el tiempo estas características políticas a través de un profundo sentimiento de amistad por los hombres ( $\varphi \iota \lambda \alpha \dot{\alpha} v \theta \omega \pi$ ) $)$, al igual que el amor por

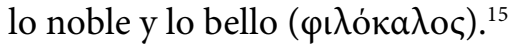

Para Plutarco es evidente que el deseo de llevar una vida política y social representa una condición innata en el ser humano. ${ }^{16}$ Por eso, desde esta perspectiva filosófica, la fábula de Babrio invita a pensar en la vejez como la máxima expresión de la vida social y política del animal racional, pues, con el paso del tiempo, estas disposiciones se robustecen en los hombres ancianos. En esta etapa de la vida se da el florecimiento de importantes virtudes políticas como la precaución

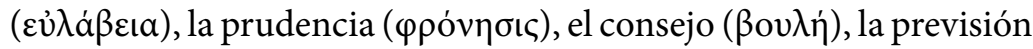

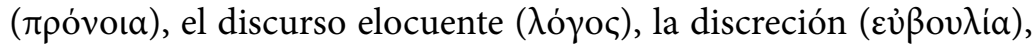

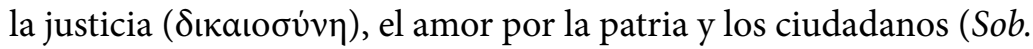
Anc. 791cd). Virtudes políticas que son fundamentales para la

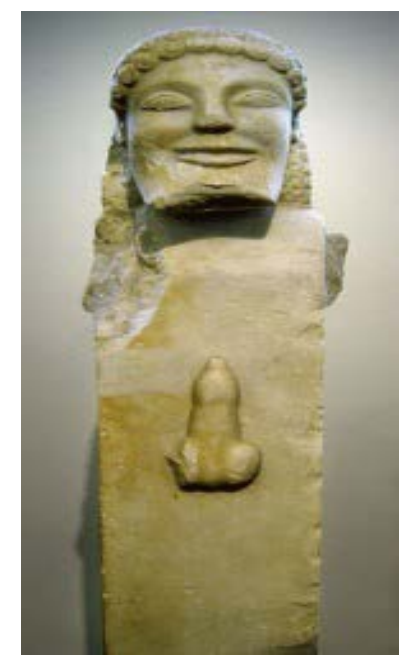

Ilustración 1: Herma griega arcaica. Símbolo de la inteligencia de los ancianos. Cf. Plutarco, 797f.

De lo anterior se deduce que la participación política del anciano es necesaria para los asuntos públicos

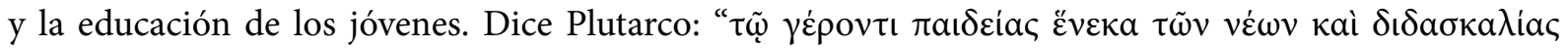

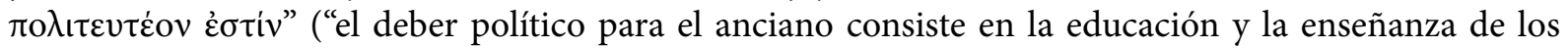
jóvenes" 790e). Virtudes y actividades que se manifiestan con mayor intensidad durante la vejez del

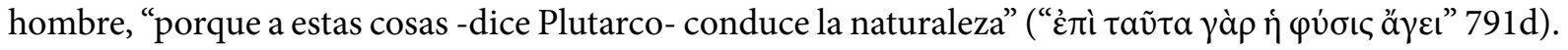
En este sentido, la condición del caballo viejo en la fábula de Babrio se puede traducir como consecuencia

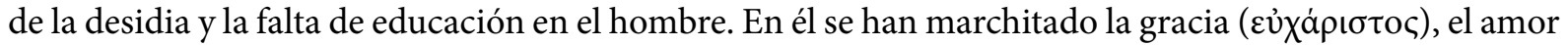

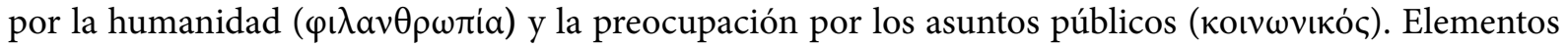
que no deberían envejecer, ni pasar ( $\pi \varepsilon \rho \alpha ́ \omega)$, ni tener fin ( $\tau \varepsilon \lambda \varepsilon v \tau \alpha \dot{\omega} \omega)$ (Sob. Anc. 792d).

Por otra parte, el desgaste del cuerpo tampoco es una excusa para que la vejez se considere como una etapa miserable de la vida. Los ejemplos historiográficos que mencionan Cicerón y Plutarco ilustran con suficiente evidencia que muchos hombres longevos fueron más útiles cuando se hicieron más viejos. Así sucedió con Agesilao (Sob. Anc. 784ef), César (784d), Pericles (784e), Catón (790cd), Pompeyo (785f), Solón (Cicerón De la vejez 26), Sexto Elio, Tiberio Coruncanio, Publio Craso (27), Ciro (30) y Lucio Metelo (30).

Con el exemplum de estos personajes, ambos filósofos plantean que la vejez es una etapa de la vida propicia para desentenderse naturalmente de los placeres que estremecen los cuerpos juveniles, lo que permite a los ancianos ocuparse de los placeres que son necesarios para la vida política (Sob. Anc. 786a).

15 Ser "amigo de los hombres" ( $\varphi \iota \lambda \alpha ́ v \theta \rho \omega \pi \circ \varsigma)$ como característica del estadista o "amante de la humanidad"

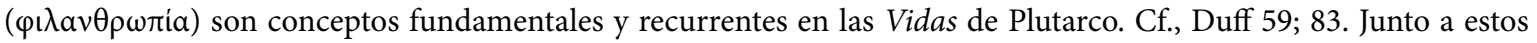
conceptos también aparecen en sus obras otras palabras compuestas de gran importancia para comprender las Vidas,

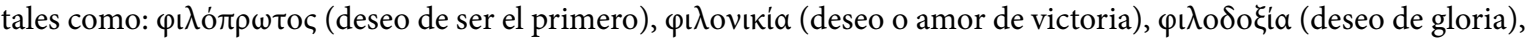

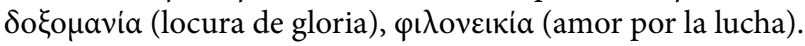

16 Al igual que para Platón Leyes 766a y Aristóteles Ética Eudemia 1242a, 22-26. 
Aquellos placeres -dice Cicerón- se encuentran en el alma: "qua voluptate animi nulla certe potest esse maior" (De la vejez 50). Entre ellos se mencionan las artes (9), la investigación de la naturaleza (49) la escritura (50) y el recuerdo de los antiguos actos (Sob. Anc.786df) que han derivado en los grandes

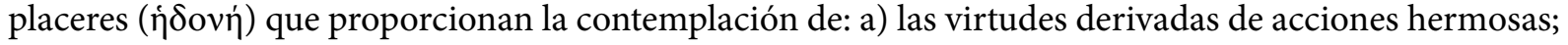
b) las virtudes derivadas de las obras que sirven al bien común y, c) las virtudes derivadas de obras que sirven a la humanidad (Sob. Anc.786c). Placeres que, como lo hacen notar ambos filósofos, se encuentran especialmente en las narraciones de la literatura épica, trágica e historiográfica, en las que resaltan por su propio brillo las más bellas acciones que agradan a los dioses (786b) y que procuran grandeza ( $\mu \varepsilon \dot{\gamma \varepsilon} \theta$ oc) y magnanimidad ( $\varphi \rho o ́ v \eta \mu \alpha)$ en el hombre (786d).

Un argumento contra la participación política de los ancianos dice que ellos están más cerca de la muerte. La falsedad de este juicio se refuta si se admite que ellos no son los únicos amenazados por la muerte; todos los seres humanos son mortales y cualquiera puede terminar sus días natural o repentinamente sin importar la edad (Cicerón De la vejez 68). Por otro lado, los filósofos antiguos no vincularon la vida buena con la prolongación biológica de la existencia. Para ellos, el valor de la vida humana se estima desde el horizonte de la ética y se comprende como una ocasión para obrar el bien o para obrar el mal, como dice Séneca: "la vida no es un bien, ni un mal: es la ocasión para el bien o para el mal". (Ep. 99.12). ${ }^{17}$ Así pues, a la luz de una mirada ética, la importancia del anciano no se mide en términos de aquel que ha vivido mucho tiempo, sino de aquel que realmente ha tenido una amplia ocasión para obrar el bien y evitar el mal en provecho de sus propios intereses y el de los demás.

La juventud también es una ocasión para obrar el bien al aprender y obedecer las enseñanzas de los ancianos. Para cada etapa de la vida, según Cicerón, se dan diferentes modos de ser (Sobre la vejez 33): en los niños se da la falta de fuerza (infirmitas), en los jóvenes el coraje (ferocitas), en los adultos la gravedad (gravitas) y en la vejez la maduración (maturitas). Por su parte, Plutarco afirma que lo propio

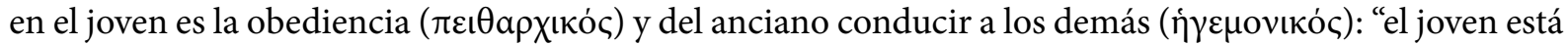

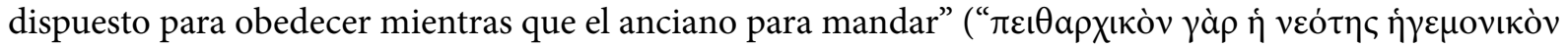
$\delta \varepsilon \dot{~ \tau o ̀ ~} \gamma \tilde{\eta} \rho a c^{\prime \prime}$ Sob. Anc. 789d). ${ }^{18}$ Dicho así, los jóvenes deben obedecer y estar bajo la tutela de los ancianos para adquirir experiencia y mejorar sus aptitudes políticas con el propósito de asumir, como conviene, los asuntos públicos (791a). Y, aunque mandar se considera lo natural y lo más propio de los ancianos, ellos mismos se deben someter y servir al Estado por causa de la juventud (791b), es decir, se vincula el servicio que los mayores deben prestar con los políticos novatos.

Por último, las consideraciones filosóficas y políticas de Cicerón y Plutarco sobre la vejez permiten entrever cierta influencia de Platón. ${ }^{19}$ Según Alsina, la reivindicación de la vejez obedece a una actitud política de este último filósofo, pues "la política de su época daba un papel demasiado grande a la juventud, con su irreflexión, su $\pi \lambda \varepsilon \varepsilon_{\varepsilon \varepsilon} \xi i a$, su brutalidad” (64). Posiblemente, Cicerón y Plutarco también se vieron en la urgente necesidad de discutir la preponderancia concedida a la juventud ante el detrimento de la

17 Traducción de Ismael Roca Meliá (DeAgostini, 1995).

18 Así opina Platón al considerar que los ancianos ( $\pi \rho \varepsilon \dot{\sigma} \sigma u \varsigma)$ deben comandar, mientras que los más jóvenes deben obedecer. Cf., Platón República III, 412c.

19 Es importante mencionar que Platón utiliza una metáfora animal cuando habla en boca de Sócrates sobre la formación de los jefes del Estado, al compararlos con potros o caballos jóvenes ( $\pi \tilde{\omega} \lambda$ oఢ) que deben ser puestos a prueba. Cf., Platón República III, 413d. 
participación política de los ancianos. Estos antecedentes políticos y sociales, tanto en la Grecia de Platón como en la Roma de Cicerón, explican la emergencia de una vejez anquilosada, débil, negligente, estática y abandonada para la que se instituyó, según Plutarco, un dicho popular: "ï $\pi$ ov $\gamma \tilde{\eta} \rho a \varsigma^{\prime}$ ” "caballo viejo" (Sob. Anc. 785d). Dicho que agrega sentido a la imagen del caballo viejo mencionado en la fábula de Babrio. Imagen que se refiere a la condición miserable de la vejez si y solo si el estadista se convierte en un anciano inútil para los asuntos públicos.

\section{Aporte final desde Los longevos}

La lista de hombres virtuosos que alcanzaron fama por su vejez es amplia. En este sentido, la exclusión y el menosprecio del anciano en torno a los asuntos públicos debe ser entendida como una muestra de ignorancia de los jóvenes políticos que desconocen la historia de su patria. Los datos aportados por Luciano permiten visualizar algunos excelentes ejemplos para ilustrar una vejez activa y floreciente ${ }^{20}$.

En este escrito el autor se dirige a uno de los Quintilios, gobernador romano de Grecia, y le desea larga vida en su gobierno como si su existencia y mando representaran una ocasión para el beneficio de la humanidad (1). Aprovechando el momento y el motivo, el autor expone la longevidad que alcanzaron algunos reyes, generales, filósofos, historiadores, poetas, gramáticos y oradores mediante el cuidado del cuerpo y del alma (2).

Los ejemplos inician con Néstor, Tiresias, las castas de los escribas egipcios, los exégetas de relatos árabes y asirios y los brahmanes de la India (3-4). ${ }^{21}$ Luego menciona la larga vida de los magos persas, partos, bactrianos, corasmianos, arios, sacas, medos y otros pueblos bárbaros que, a diferencia de los griegos, prolongaron su existencia a través de la magia (4).

Las causas de la longevidad también se asocian con la dieta, el clima, el suelo, y los ejercicios gimnásticos (5- 6). De cualquier modo, ya sea por el alimento, el territorio, el género de vida o por efectos de la magia en el cuerpo, se tiene noticia de la vejez sana y prolongada de algunos personajes bárbaros, griegos y romanos.

A partir de la figura 1 se puede decir que entre los reyes y generales Argantonio, rey de los tartesios, fue el más anciano de todos con 150 años de edad y seguido por los 100 años de Ciro el viejo. Periodos de vida tan prolongados que rayan con la fantasía y lo asombroso para entretener al lector.

El filósofo Jenófilo vivió 105 años y 104 Demócrito de Abdera. Gorgias el sofista vivió 108 años y los historiadores más longevos, según las noticias que proporciona Luciano, fueron Jerónimo y Ctesibio con 104 años cada uno. Entre los reyes y generales se observa que Servio Tulio y Agatocles vivieron 90 años, al igual que Asandro y Masinisa. El sofista Isócrates vivió 99 años, mientras que los poetas más ancianos fueron Epicarmo, Cratino, Sófocles y Simónides de Ceos que vivió más de 90 años (26).

20 Muchos investigadores no reconocen la autoría de Luciano para este escrito. Sobre el debate véase la nota introductoria en la edición de Gredos 1981.

21 Néstor fue una de las figuras más representativas de la vejez en la antigüedad clásica por su sabiduría y servicio militar a los Aqueos durante la Guerra de Troya. Cf., Cicerón De la vejez, 31; Plutarco Sob. Anc. 788ab. 
Entre todos los individuos la mínima edad de defunción es de 80 años. El gráfico (c) de la figura 2 permite decir que entre los oradores se encuentra la mayor longevidad con un promedio de $94,8 \%$, pero se debe tener en cuenta que ellos tienen el menor número de individuos, tal como lo indica la gráfica (a) de la figura 2 con un $7 \%$.

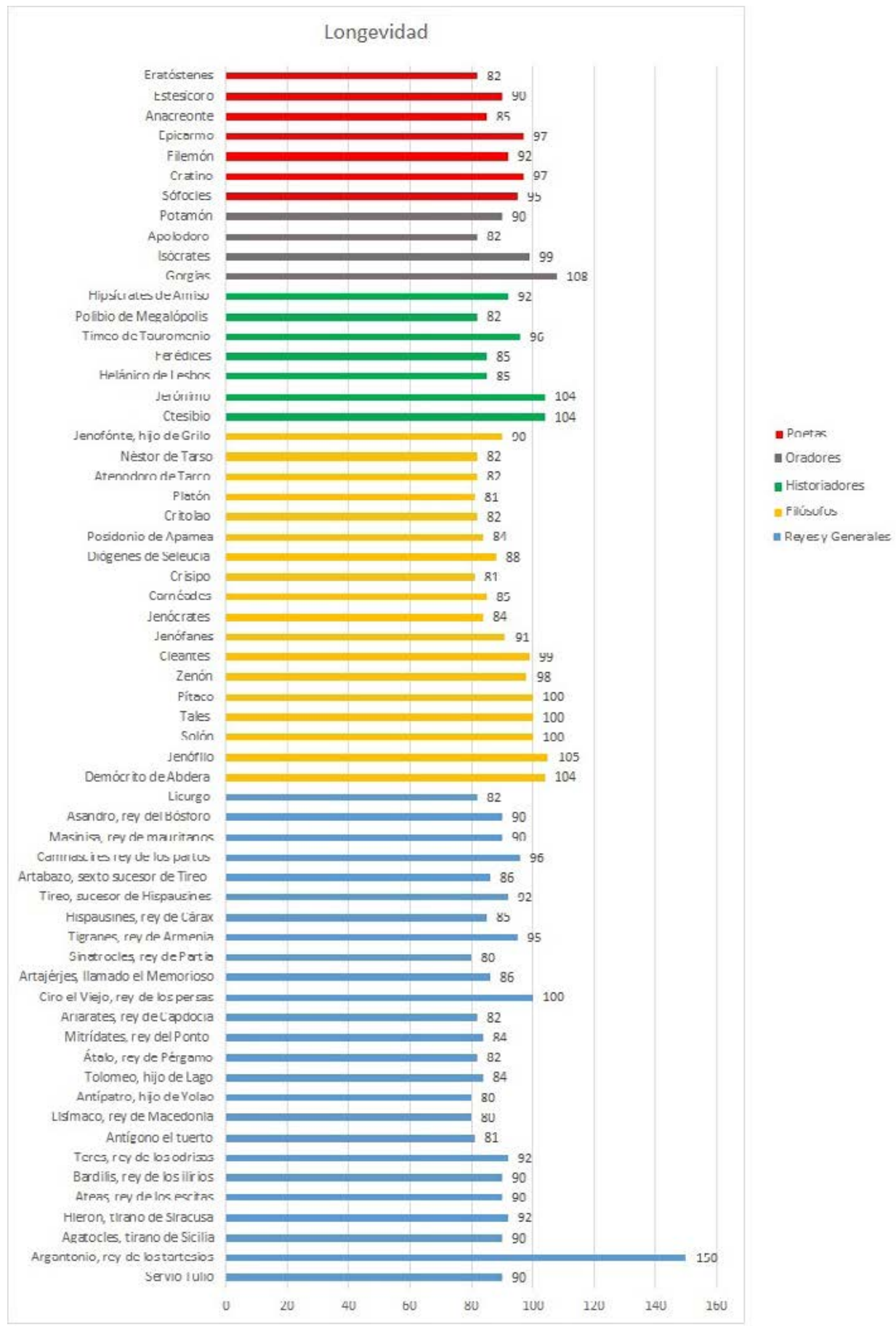

Ilustración 2: Figura 1. Longevidad de los individuos seleccionados por género de vida. 
También se puede decir que la longevidad entre los reyes y generales es la menor con un promedio de 90 años. Deducción sorprendente, sin lugar a dudas, para este género de vida, al tratarse de una profesión expuesta a muchísimos peligros.

La gráfica (b) de la figura 2 indica que el $44 \%$ de los individuos vive entre los 80 y los 89 años de edad, un $41 \%$ vive entre los 90 y los 99 años, mientras que solo un $15 \%$ alcanza o supera los cien años.

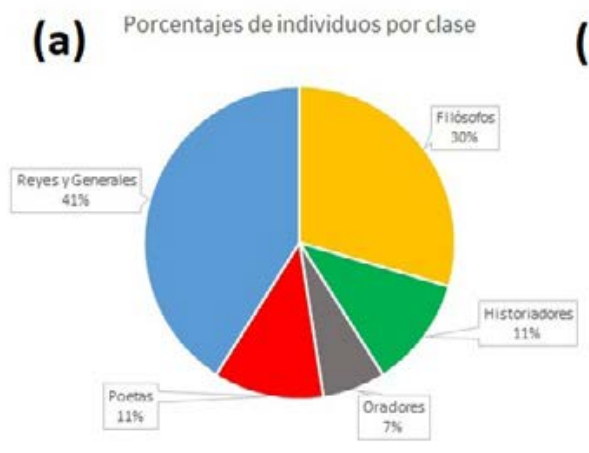

(b) Porcentajes de longevidad en todas los individuos

(c)
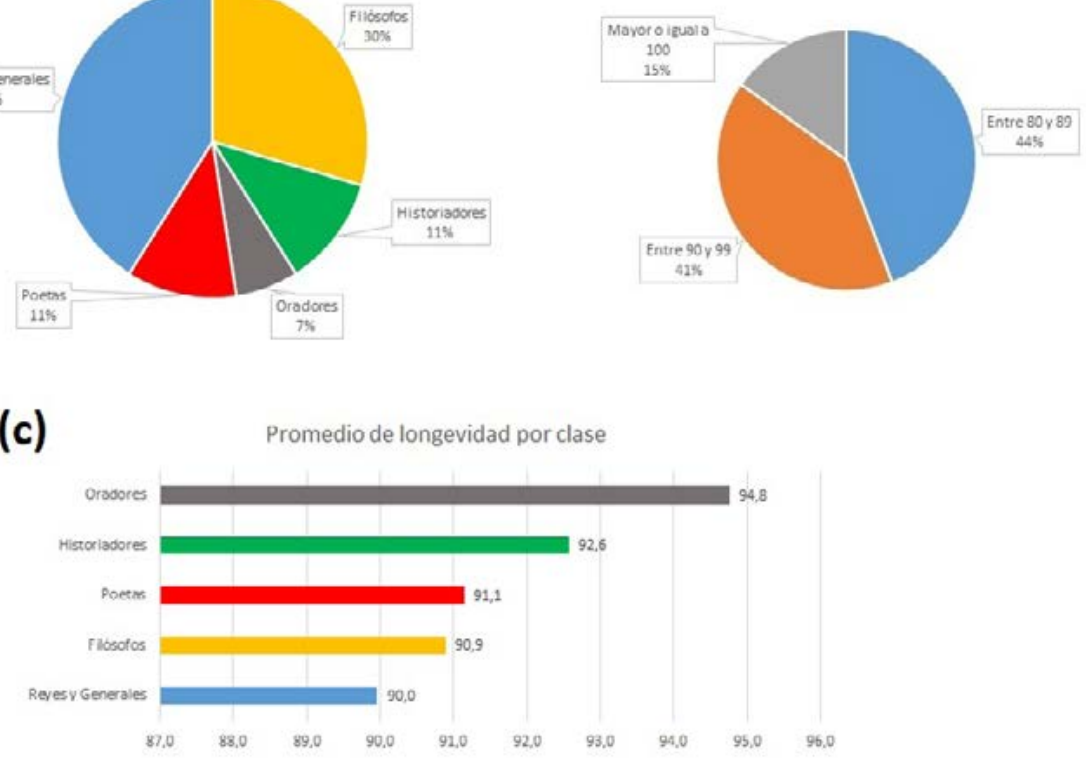

Ilustración 3: Figura 2 Análisis descriptivo de los individuos por género de vida y clasificación de longevidad.

El mayor porcentaje de longevidad entre los 90 y 99 años de edad se presenta en los poetas con un 71 $\%$ de individuos, tal como lo indica la gráfica (c) de la figura 3. En la gráfica (d) de la misma figura se observa que entre los filósofos, el $50 \%$ de los individuos vivió entre los 80 y 89 años, mientras que el $50 \%$ de los oradores entre los 90 y 99 años, según la gráfica (a) de la figura 3. Solo un $8 \%$ de los reyes y generales, de acuerdo con la gráfica (e) de la misma figura, alcanzó una longevidad igual o mayor a los 100 años, porcentaje que entre historiadores y los filósofos es del $29 \%$ y 28\%, respectivamente, según las gráficas (b) y (d) de la figura 3.

Si se tiene en cuenta la información suministrada por Luciano, se puede decir que la edad de algunos dirigentes políticos osciló entre los 80 y los 89 años, lo que representa el $48 \%$ de la longevidad entre todos los individuos que pertenecen a este género de vida. Esta cifra hace verosímil considerar que muchas veces la dirección del pueblo realmente estuvo en manos de reyes y generales ancianos para confirmar los argumentos en favor de la vejez tanto en Plutarco como en Cicerón. Sin embargo, se debe tener en cuenta que estos individuos pertenecían a grupos privilegiados y gozaban de una buena condición social y económica que les facilitó alcanzar una edad avanzada. Además, en el caso de Roma este fenómeno solo 

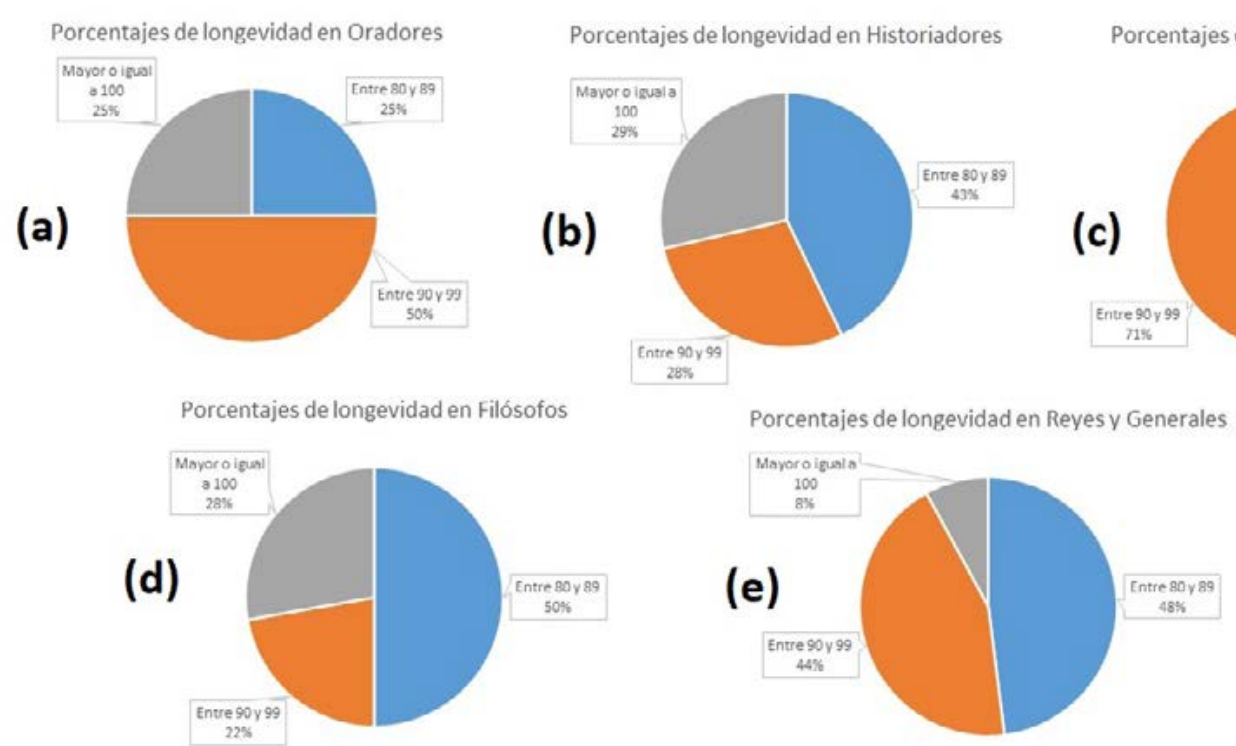

Ilustración 4: Figura 3. Análisis de clasificación por periodos de edad dentro de cada género de vida.

puede representar una condición excepcional para una sociedad en la que la esperanza de vida entre los hombres y las mujeres del común alcanzaba entre 20 y 30 años de edad, respectivamente (Torrego 211). Por eso, muy probablemente los reyes y generales más ancianos hicieron parte de un grupo privilegiado de la sociedad y tuvieron mayores posibilidades de alcanzar una edad avanzada gracias a su estatus social y a las facilidades económicas garantizadas por su dignidad. Sin embargo, las fuerzas de la juventud pueden ocasionar un venturoso desequilibrio político entre los viejos y los nuevos dirigentes. Fenómeno que cautivó la reflexión de Plutarco y de Cicerón en tanto representaba para ambos filósofos un grave peligro para la sociedad. De ahí, el interés filosófico que expresan sus escritos y el afán de reconciliar al joven y al anciano para que la próxima generación de estadistas evite el penoso destino del "iٓ $\pi$ rov $\gamma \tilde{\eta} \rho a c$ " que narra la fábula de Babrio.

\section{Conclusión}

Hasta aquí se ha presentado una interpretación filosófica y política de la fábula El caballo viejo. Se incluyeron, para su reflexión, dos textos filosóficos: De la vejez, de Cicerón y Sobre si el anciano debe intervenir en política, de Plutarco. Al final, se hizo un breve análisis estadístico a partir de los datos que aporta Luciano en Los longevos con el propósito de confirmar los argumentos de Plutarco y Cicerón en torno a una vejez prolongada y activa.

Una lectura apresurada de la fábula puede hacer pensar que la vejez es una condición miserable en sí misma. Sin embargo, después de analizar la fábula, queda claro que la vejez solo es miserable cuando el político llega a convertirse en un estadista inútil que no supo aprovechar las fuerzas de la juventud. Al respecto, Plutarco dice que los ancianos despreocupados por los asuntos públicos recibieron en Grecia el

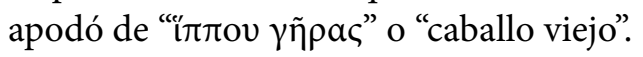


Aprovechar la juventud para lograr una vejez bien llevada constituye el aspecto positivo del epimythium o la moraleja de la fábula. Esta es la idea que también reflejan los argumentos y ejemplos de Cicerón y de Plutarco.

Ambos filósofos prueban la insuficiencia de las razones según las cuales se dice que la vejez debilita el cuerpo y priva casi todos los placeres y aproxima más el fin de la existencia que obliga al hombre longevo a desestimar los negocios púbicos.

En primer lugar, estos filósofos hacen comprender que los ancianos son miembros de la polis cuya condición sagrada se vincula con la patria y con los dioses del Estado; segundo, los ancianos prueban que el ser humano sirve más y mejor cuando la vejez proporciona virtudes políticas como la precaución

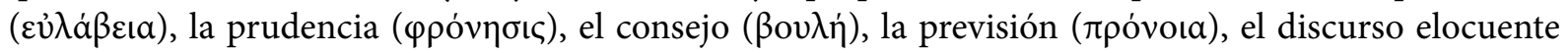

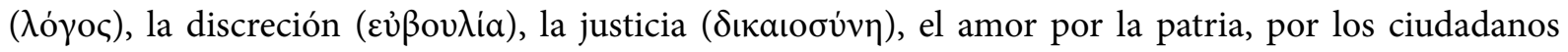
y por la humanidad ( $\varphi \iota \lambda \alpha \nu \rho \omega \pi i \alpha)$; tercero, los ancianos en verdad se desembarazan de los placeres físicos, pero disfrutan otros placeres que comprometen el alma, tales como: las artes, la investigación de la naturaleza, la escritura, el recuerdo de los antiguos actos relacionados con las acciones hermosas, las obras que sirven al bien común y las que sirven a la humanidad. Finalmente, la vejez no es la única etapa de la vida en la que se está más cerca de la muerte, pues el ser humano puede morir en cualquier instante. Estos argumentos filosóficos y políticos permiten ampliar la comprensión de la fábula. Un relato que estimula la reflexión sobre el rol de los ancianos en la sociedad y la participación política de los jóvenes que, con una vida bien llevada, pueden evitar convertirse en el próximo "caballo viejo" del Estado.

\section{Referencias}

\section{Obras clásicas y traducciones}

Alsina Clota, José. (trad.). Luciano. Obras. Vol. I, Madrid: Gredos, 1981.

Badenas, Pedro. y López Facal, Javier. (trads). Fábulas de Esopo. Vida de Esopo. Fábulas de Babrio. Madrid: Gredos, 1985. Crusius, Otto [ed.]. Babrii Fabulae Aesopeae, Lipsiae: B. G. Teubner, 1897.

García Gual, Carlos. (trad.). Diógenes Laercio. Vidas y opiniones de los filósofos ilustres. Madrid: Alianza, 2007.

Lisi, Francisco. (trad.), Platón. Leyes. Madrid: Gredos, 1999.

Pimentel Álvarez, Julio. (trad.). Cicerón. Catón el mayor: De la vejez. Lelio: de la amistad. México: UNAM, 1997.

Pallí Bonet, Julio. (trad.). Aristóteles. Ética Eudemia., Madrid: Gredos, 1993.

Roca Meliá, Ismael. (trad.), Séneca. Epístolas morales a Lucilio. Argentina: Planeta-DeAgostini, 1995.

Valverde S. M., Rodríguez S. H. y Alcalde M. C. (trads.). Plutarco. Obras morales y de costumbres X. Madrid: Gredos, 2003.

\section{Literatura complementaria}

Alsina, C. J. "Platón y la vejez", Helmántica: Revista de filología clásica y hebrea 5.16-18 (1954): 61-69. https://doi. org/10.36576/summa.2417

Coulanges, Fustel. La ciudad Antigua. Estudios sobre el culto, el derecho, las instituciones de Grecia y Roma. Panamericana: Bogotá, 1997.

Duff, Tim. Plutarch's Lives, Exploring Virtue and Vice. New York: Oxford University Press, 1999.

García Gual, Carlos. Los siete sabios (y tres más). Madrid: Alianza, 1989.

Pabón, José María. Diccionario Vox. Manual Griego Clásico-Español. España, De Urbina. Blackprint, 2012. 
Perry, Ben Edwin. “The Origin of the Epimythium”. Source: Transactions and Proceedings of the American Philological Association 71 (1940): 391-419. https://doi.org/10.2307/283136

Raquena, Miguel. Lo maravilloso y el poder. Los presagios de imperio de los emperadores Aureliano y Tácito en la Historia Augusta. Valencia: Universidad de Valencia: PUV, 2003.

Rodríguez Adrados, Francisco. "La fábula griega como género literario". En Fernández Delgado, J.A. (ed.), Estudios de forma y contenido sobre los géneros literarios. Cáceres: Universidad de Extremadura, 1982, 33-46.

Rodríguez Adrados, Francisco. "Más sobre la fábula" "More on the Greek fable and its origins". Emérita. Revista de Lingüística y Filosofía Clásica, LXXXII, (2014), 345-351. https://doi.org/10.3989/emerita.2014.08.1417

Rodríguez Adrados, Francisco. "Política Cínica en las fábulas esópicas". En Filología e forme letterarie stodi offerti a Francesco Della Corte, I, Urbino, 1987, 413-26.

Torrego, Esperanza. "La vejez en Roma: el reflejo y la vivencia". En Las edades del hombre. Las etapas de la vida entre griegos y romanos. Hernández Crespo, R. M. -Domínguez Monedero, A. J. (eds.). Madrid, Sociedad Española de Estudios Clásicos, 2014. 